\title{
O ENSINO DA ESTATÍSTICA E DA PROBABILIDADE NA EDUCAÇÃO BÁSICA E A FORMAÇÃO DOS PROFESSORES
}

\author{
Celi Espasandin Lopes*
}

\begin{abstract}
RESUMO: Este artigo trata sobre a relevância e os objetivos para se ensinar e aprender estatística e probabilidade na Educação básica. A partir dos resultados de pesquisas realizadas na Educação estatística e na Educação Matemática nas últimas décadas, traz consideraçōes sobre os processos de ensino e aprendizagem da estocástica durante a infância e adolescência. Apresenta recomendaçōes relativas ao currículo de Matemática no que se refere ao estudo da probabilidade e da estatística. Destaca questôes relativas à formação inicial e contínua dos professores, ao desenvolvimento profissional e conhecimento profissional dos professores que ensinam matemática na educação infantil, ensino fundamental e médio.
\end{abstract}

Palavras-chave: Educação básica. Educação Matemática. Educação estatística. Probabilidade. Formação de professores.

\section{THE TEACHING OF STATISTICS AND PROBABILITY AT ELEMENTARY SCHOOLS AND TEACHER EDUCATION}

ABSTRACT: This paper is about the relevance and goals of teaching and learning about statistics and probability in basic education. From results of researches carried out in statistics education in mathematics education, in the last few decades, it brings up considerations about the stochastic teaching and learning process during childhood and adolescence. The text also presents recommendations related to the mathematics curriculum referring to the study of probability and statistics. It highlights issues related to teacher education both in the beginning of their careers and along

Doutora em Educação e professora titular do Programa de Mestrado em Ensino de Ciências e Matemática da Universidade Cruzeiro do Sul (UnICSUL). E-mail: celilopes@uol.com.br 
their professional lives, professional development and professional knowledge of professionals who teach mathematics at kindergarten, elementary, middle school and secondary school levels.

Key words: Basic education. Mathematics education. Statistics education. Probability. Teacher education.

\section{Introdução}

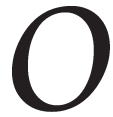

objetivo desse artigo é promover uma discussão sobre a inserção da estatística e probabilidade no currículo de Matemática desde os anos iniciais da escola básica e as possíveis relações e/ou implicações com a formação de professores que atuam nesse nível de ensino.

As propostas curriculares de matemática têm procurado justificar a importância e a relevância desses temas na formação dos estudantes, pontuando o que eles devem conhecer e os procedimentos que devem desenvolver para uma aprendizagem significativa. O estudo desses temas torna-se indispensável ao cidadão nos dias de hoje e em tempos futuros, delegando ao ensino da matemática o compromisso de não só ensinar o domínio dos números, mas também a organização de dados, leitura de gráficos e análises estatísticas.

Sob esta visão, percebemos que se incluirmos a estocástica ${ }^{1}$ apenas como um tópico a mais a ser estudado, em um ou outro ano de escolaridade da educação básica, enfatizando apenas a parte da estatística descritiva, seus cálculos e fórmulas não levarão o estudante ao desenvolvimento do pensamento estatístico e do pensamento probabilístico, que envolvem desde uma estratégia de resolução de problemas, até uma análise sobre os resultados obtidos. Parece-nos essencial à formação de nossos alunos o desenvolvimento de atividades estatísticas que partam sempre de uma problematização, pois assim como os conceitos matemáticos, os estatísticos também devem estar inseridos em situaçôes vinculadas ao cotidiano deles. Assim sendo, esse estudo os auxiliará na realização de seus trabalhos futuros em diferentes ramos da atividade humana e contribuirá para sua cultura geral (Lopes, 1998).

Acreditamos que é necessário desenvolver uma prática pedagógica na qual sejam propostas situações em que os estudantes realizem atividades, as quais considerem seus contextos e possam observar e construir os eventos possíveis, por meio de experimentação concreta, de 
coleta e de organização de dados. A aprendizagem da estocástica só complementará a formação dos alunos se for significativa, se considerar situações familiares a eles, que sejam contextualizadas, investigadas e analisadas.

Para isso, acreditamos ser necessária uma visão curricular para a Matemática que seja diferente da linear. A linearidade tem predominado nos currículos dessa disciplina, sempre justificando que, para ensinar um conteúdo, é preciso antes trabalhar seu antecedente. Segundo D'Ambrosio (1998), esse é o mito da linearidade, que implica uma prática educativa desinteressada e desinteressante, desinspirada, desnecessária, acrítica e, na maioria das vezes, equivocada.

O ensino da estocástica talvez possa auxiliar na ruptura dessa prática linear, considerando que os conceitos a serem trabalhados podem ser extraídos de problemáticas diversas, sem se prenderem a um determinado ano da escolaridade.

\section{A relevância do ensino da probabilidade e da estatística}

O desenvolvimento da estatística e da probabilidade, nas escolas básicas, tem sido alvo de pesquisas em algumas partes do mundo, e muitos pesquisadores publicam trabalhos a respeito, procurando justificar a relevância do assunto. De acordo com Shaughnessy (1992, 2007), a pesquisa em estocástica tem sido verdadeiramente interdisciplinar. Educadores matemáticos e estatísticos contribuíram amplamente, nos últimos dez anos, e o estágio de pesquisa apresenta-se demais eclético para que seja possível uma síntese. A partir dos resultados dessas pesquisas, apresentaremos consideraçóes e/ou recomendações sobre o ensino e a aprendizagem da estocástica.

No início dos anos de 1980, Mendoza e Swift (1981) destacaram que estatística e probabilidade deveriam ser ensinadas para que todos os indivíduos pudessem dominar conhecimentos básicos de estatística e probabilidade para atuarem na sociedade. Atualmente, as propostas curriculares de matemática, em todo mundo, dedicam atenção especial a esses temas, enfatizando que o estudo dos mesmos é imprescindível para que as pessoas possam analisar índices de custo de vida, realizar sondagens, escolher amostras e tomar decisões em várias situações do cotidiano. 
A competência nesses assuntos permite aos alunos uma sólida base para desenvolverem estudos futuros e atuarem em áreas científicas como a biologia e as ciências sociais. Além disso, ao considerarmos o mundo em rápida mudança como o que estamos vivendo, é imprescindível o conhecimento da probabilidade de ocorrência de acontecimentos para agilizarmos a tomada de decisão e fazermos previsóes.

Por termos vivenciado algumas situações de pesquisa e orientação de professores no que se refere ao ensino da estatística e da probabilidade na educação infantil, no ensino fundamental e no ensino médio, consideramos mais amplamente as contribuiçôes do estudo desses temas à formação do aluno. Verificamos o objetivo de desenvolvermos a capacidade de crítica e a autonomia desse aluno para que exerça plenamente sua cidadania, ampliando suas possibilidades de êxito na vida pessoal e profissional. Não estamos dizendo com isso que apenas o estudo desses temas seja suficiente, mas sem dúvida permite ao estudante desenvolver habilidades essenciais, como análise crítica e argumentação. Tais assuntos são tão importantes no currículo de matemática da educação básica quanto o estudo da geometria, da álgebra ou da aritmética que, trabalhadas significativamente, também contribuem para essa formação.

Não basta ao cidadão entender as porcentagens expostas em índices estatísticos, como o crescimento populacional, taxas de inflação, desemprego... É preciso analisar/relacionar criticamente os dados apresentados, questionando/ponderando até mesmo sua veracidade. Assim como não é suficiente ao aluno desenvolver a capacidade de organizar e representar uma coleção de dados, faz-se necessário interpretar e comparar esses dados para tirar conclusões.

No mundo das informações no qual estamos inseridos, torna-se cada vez mais "precoce" o acesso do cidadão a questôes sociais e econômicas em que tabelas e gráficos sintetizam levantamentos; índices são comparados e analisados para defender idéias. Dessa forma, faz-se necessário que a escola proporcione ao estudante, desde os primeiros anos da escola básica, a formação de conceitos que o auxiliem no exercício de sua cidadania. Entendemos que cidadania também seja a capacidade de atuação reflexiva, ponderada e crítica de um indivíduo em seu grupo social. Sendo assim, urge que a escola cumpra seu papel de educar para a cidadania. Segundo Machado (1997, p. 48), 
(...) educar para a cidadania deve significar também, pois, semear um conjunto de valores universais, que se realizam com o tom e a cor de cada cultura, sem pressupor um relativismo ético radical francamente inaceitável; deve significar ainda a negociação de uma compreensão adequada dos valores acordados, sem o que as mais legítimas bandeiras podem reduzir-se a meros slogans e o remédio pode transformar-se em veneno. Essa tarefa de negociação, sem dúvida, é bastante complexa; enfrentála, no entanto, não é uma opção a ser considerada, é o único caminho que se oferece para as ações educacionais.

Para que o ensino da estatística e da probabilidade contribua para a efetivação desse fato, é importante que se possibilite aos alunos o confronto com problemas variados do mundo real e que tenham possibilidades de escolherem suas próprias estratégias para solucioná-los. Acreditamos ser necessário que nós, professores, os incentivemos a socializarem suas diferenciadas soluções, aprendendo a ouvir críticas, a valorizar seus próprios trabalhos e os dos outros. Nesse contexto, o trabalho com esses temas pode ser de grande contribuição, tendo em vista sua natureza problematizadora que viabiliza o enriquecimento do processo reflexivo.

Dessa forma, defendemos que os conceitos probabilísticos e estatísticos devam ser trabalhados desde os anos iniciais da educação básica para não privar o estudante de um entendimento mais amplo dos problemas ocorrentes em sua realidade social.

Não é possível esperarmos que nosso aluno chegue ao ensino médio para iniciarmos conteúdos essenciais para o desenvolvimento de sua visão de mundo. É preciso que a escola proporcione a ele instrumentos de conhecimento que lhe possibilitem uma reflexão sobre as constantes mudanças sociais e o prepare para o exercício pleno da cidadania. Nesse sentido, D’Ambrósio (1996, p. 87) nos aponta: "A educação para cidadania, que é um dos grandes objetivos da educação de hoje, exige uma 'apreciação' do conhecimento moderno, impregnado de ciência e tecnologia”.

Assim, consideramos que o trabalho com estatística e probabilidade torna-se relevante ao possibilitar ao estudante desenvolver a capacidade de coletar, organizar, interpretar e comparar dados para obter e fundamentar conclusóes, que é a grande base do desempenho de uma atitude científica. Esses temas são essenciais na educação para a cidadania, uma vez que possibilitam o desenvolvimento de uma análise crítica sob diferentes aspectos científicos, tecnológicos e/ou sociais. 
Uma educação estatística crítica requer do professor uma atitude de respeito aos saberes que o estudante traz à escola, que foram adquiridos por sua vida em sociedade. Em nosso modo de entender, seria necessária a discussão de temas, como a poluição dos rios e mares, os baixos níveis do bem-estar das populações, o abandono da saúde pública, entre outros; questões que estão em manchetes de jornais diários e revistas e em reportagens de televisão. Trabalhando a análise dessas questões que estão sempre envolvidas em índices, tabelas, gráficos etc., podemos estar viabilizando a formação de cidadãos críticos, éticos e reflexivos.

Dessa forma, estatística e probabilidade, em sala de aula, poderiam ser temas explorados por meio da matematização, entendendo, segundo a definição de Skovsmove (1994), que matematizar significa, em princípio, formular, criticar e desenvolver modos de compreensão. Para que esse processo se efetive é necessário que tanto alunos quanto professores estejam no domínio da situação de aprendizagem, elaborando e solucionando problematizações.

\section{O ensino da probabilidade e da estatística através da resolução de problemas}

A resolução de problemas, que é o princípio norteador da aprendizagem da matemática, pode possibilitar o desenvolvimento do trabalho com estatística e probabilidade em sala de aula, pois da mesma forma que a matemática, a estatística também se desenvolveu através da resolução de problemas de ordem prática na história da humanidade.

Assim, é preciso entender que problema não é um exercício de aplicação de conceitos recém-trabalhados, mas o desenvolvimento de uma situação que envolve interpretação e estabelecimento de uma estratégia para a resolução. Pozo (1998) considera que trabalhar problema em matemática significa colocar em ação certas capacidades de inferência e de raciocínio geral.

Acreditamos que não faz sentido trabalharmos atividades envolvendo conceitos estatísticos e probabilísticos que não estejam vinculados a uma problemática. Propor coleta de dados desvinculada de uma situação-problema não levará à possibilidade de uma análise real. Construir gráficos e tabelas desvinculados de um contexto ou relacionados a situações muito distantes do aluno pode estimular a elaboração de um pensamento, mas não garante o desenvolvimento de sua criticidade. 
Uma vez mais ressaltamos que o ensino da estocástica deve propiciar ao estudante situações que lhe permitam a superação do determinismo em favor da aleatoriedade. É necessário trabalharmos dentro do currículo de Matemática com situações que envolvam as idéias de acaso e de aleatório, pois, do contrário, estaremos reduzindo o ensino desta ao verdadeiro e falso de suas proposições. Bernardes (1987, p. 13) afirma que: "Se o ensino de Matemática se deve ocupar mais de uma forma de pensar do que de uma forma de escrever fórmulas ou numerais, se o ensino da Matemática se deve ocupar mais da tomada consciente de decisões do que do estrito cálculo, então a teoria das probabilidades é fundamental".

O desenvolvimento do pensamento probabilístico e estatístico, sem dúvida, pode efetivar as potencialidades formativas da disciplina de Matemática.

O ensino da matemática tem como tradição a exatidão, o determinismo e o cálculo, opondo-se à exploração de situações que envolvam aproximação, aleatoriedade e estimação, as quais podem limitar a visão matemática que o aluno poderá desenvolver, dificultando suas possibilidades de estabelecimento de estratégias para a resolução de problemas diversificados que lhe surgirão ao longo de sua vida.

Godino et al. (1987) apontam uma razão do tipo social para defender a educação da intuição probabilística na escola básica, que é tornar os alunos conscientes da natureza probabilística de distintos jogos de azar (loterias, máquinas caça-níqueis, bingos etc.), jogos que são magníficos negócios para aqueles que os promovem e um risco desproporcional de perder dinheiro para aqueles que apostam. Os autores questionam se é racional um homem ou uma mulher expor seus bens a uma casualidade tão pouco favorável para si.

Dessa forma, talvez o trabalho crítico e reflexivo com a estocástica possa levar o estudante a repensar seu modo de ver a vida, o que contribuirá para a formação de um cidadão mais liberto das armadilhas do consumo.

Consideramos que o estudo de conceitos estatísticos e probabilísticos a partir dos anos iniciais é essencial à formação da criança. No mundo atual, diariamente, cada indivíduo recebe grande quantidade de informações e, com freqüência, utiliza técnicas estatísticas para correlacionar dados e, a partir destes, tirar conclusões. Além disso, outras áreas 
do conhecimento, como Biologia, Física, Química, Geografia, entre outras, fazem uso, constantemente, da linguagem estatística. Assim, vislumbramos o ensino da estatística assumindo um papel de instrumento de operacionalização, de integração entre diversas disciplinas e mesmo entre diferentes temas dentro da própria Matemática.

Para desenvolver um trabalho pedagógico que viabilize a educação estatística de nossos estudantes, há desafios com os quais os professores que ensinam matemática na educação básica têm se confrontado.

\section{Os desafios docentes e a elaboração do conhecimento profissional}

O repensar do papel do professor no processo do ensinar e do aprender tem estado na pauta nacional de educação e tem sido foco central de algumas políticas públicas. No entanto, ainda não se podem perceber resultados significativos no que se refere à formação estocástica dos alunos que têm finalizado o ensino médio.

Inicialmente, é necessário que cada docente tenha consciência de sua ação política através de sua prática pedagógica. D’Ambrósio (1996) nos leva a refletir que educação é um ato político e se algum professor julga que sua ação é politicamente neutra, não entendeu nada de sua profissão.

Sem dúvida, o processo educacional é inerentemente político e nós, professores, constantemente tomamos decisões e assumimos ações que expressam o quanto não somos politicamente neutros. Assim, um primeiro desafio refere-se a nossa opção em incluir ou excluir alguns assuntos do currículo de nossa disciplina. Nessa ação estamos efetivando nossa posição política, quando legitimamos certas crenças e deslegitimamos outras.

Freire (1997) também considera que a produção do conhecimento com criticidade deve ser um trabalho conjunto do professor e do aluno, que o pensar certo, que supera o ingênuo, precisa ser produzido pelo próprio aprendiz, em comunhão com o professor-formador. Um segundo desafio enfrentado pelo professor é estabelecer uma relação com o aluno, na qual este se perceba produtor de conhecimento e co-responsável pelo seu processo de aprendizagem, assumindo o compromisso de socializar com seus pares suas compreensóes e dificuldades, trabalhando assim colaborativamente. 
As transformações sociais, econômicas e políticas pelas quais passa a sociedade têm solicitado um novo modelo de escola, trazendo um repensar para aqueles que exercem a função docente. D'Ambrosio (1998, p. 49), um educador matemático sempre à frente de seu tempo, com a capacidade constante de nos provocar significativas reflexões sobre o ato de educar, afirma:

Faz-se necessário um outro professor, formado de outra maneira e com a capacidade de renovar seus conhecimentos como parte integrante de sua preparação profissional. Além disso, um professor conscientizado de que seu papel tem sua ação bem mais ampliada é certamente mais empolgante do que um mero transmissor de informações na função de professor.

Tal alerta aponta para que se tenha um olhar cuidadoso em relação à formação de professores, pois já podemos considerar consenso que os cursos de reciclagem e treinamento são um modelo fracassado, uma vez que não envolvem o profissional em processos de reflexão sobre sua prática.

Azcárate (1999) considera o conhecimento profissional resultante de diferentes informaçôes provenientes de fontes distintas e organizado em torno de problemas específicos do ensino. Dessa forma, o conhecimento profissional do professor tem natureza transdisciplinar, complexa e interliga os componentes empíricos da didática. Ele é passível de múltiplas concepçôes e procedimentos, que se ampliam significativamente para os professores da educação infantil e séries iniciais do ensino fundamental, os quais são considerados polivalentes por terem várias áreas de conhecimento como foco de trabalho.

O termo "conhecimento" pode referir-se às áreas do saber pedagógico, do saber-fazer e do saber por que, uma vez que isso significa os conhecimentos teóricos e conceptuais, os esquemas práticos de ensino e a justificação da prática. Assim, podem-se elencar quatro componentes para o conhecimento profissional dos professores: $o$ conhecimento do conteúdo, o psicopedagógico, o didático do conteúdo e o do contexto (Marcelo García, 1999, p. 84).

A partir das argumentações desses teóricos, acreditamos que, então, os professores precisam possuir conhecimentos sobre a matéria que ensinam, conheçam o conteúdo em profundidade, sendo capazes de organizá-lo mentalmente, de forma a estabelecer inúmeras inter-relações, 
relacionem esse conteúdo ao ensino e à aprendizagem, em um processo de interação com os alunos, considerando o desenvolvimento cognitivo dos mesmos e, também, dominem o contexto, tendo clareza do local em que ensinam e a quem ensinam.

O elemento central do conhecimento profissional do professor é, sem dúvida, o didático do conteúdo, porém não é o suficiente. Fazse necessária uma combinação adequada entre o conhecimento sobre o conteúdo matemático a ser ensinado e o conhecimento pedagógico e didático de como ensiná-lo.

O conhecimento didático do conteúdo é uma síntese entre os conteúdos a ensinar e os modos de fazê-lo, incluindo formas de representação das idéias, analogias importantes, ilustrações e exemplos próximos ao contexto. Está incorporada a esse conhecimento a habilidade em representar e formular o conteúdo conceitual e/ou procedimental, tornando-o compreensível aos alunos, gerando a compreensão do que torna a aprendizagem de um conceito mais ou menos difícil e de suas respectivas concepções.

O professor, na sua atividade profissional diária, defronta-se com múltiplas situações para as quais não encontra respostas preestabelecidas. Para fazer-lhes face, tem de pôr em movimento um conhecimento que envolve elementos com origens diversas - incluindo acadêmicas e experiências -, bem como aspectos de foro pessoal e contextual. Em seu desempenho profissional, o docente não só precisa mobilizar teorias e técnicas, mas também suas concepções, sentimentos e seu saberfazer (Lopes, 2003).

É por isso que cada vez mais se identifica o conhecimento do professor como prático, pois integra conhecimento teórico de referência e experiencial. É pessoal, porque é construído pelo próprio docente, inserido nos vários contextos de sua atuação profissional.

Um profissional da Educação, que conceba o ensino como uma mera transmissão de conceitos já elaborados e construídos, que considere que a aprendizagem restringe-se apenas ao envolvimento e à capacidade do aluno, talvez não leve em conta os componentes do conhecimento profissional como necessidades.

A atuação docente dependerá de sua sensibilidade para com o processo de desenvolvimento dos alunos, de suas interpretaçôes do 
contexto no qual atua e de seu autoconhecimento pessoal e profissional. Talvez essas características possam ser desencadeadoras do desenvolvimento profissional.

O desenvolvimento profissional é um processo que salienta os aspectos que o professor pode desenvolver em função de suas potencialidades. Ocorre com base em um certo autodidatismo, em que ele procura, decide, projeta e executa um plano de formação. É nessa busca que melhora seu conhecimento, suas competências e/ou atitudes (Lopes, 2003).

Segundo Marcelo García (1999), o desenvolvimento profissional é muito mais que proporcionar um serviço a um professor ou a um grupo de professores. Inclui também a dinâmica organizacional da escola, como o clima, a estrutura de autoridade, as normas que definem as relações entre o pessoal, a natureza das comunicações em uma escola ou em um distrito, os papéis e responsabilidades daqueles que pertencem à organização.

Um desenvolvimento autônomo ocorre por iniciativa do próprio professor, pode ter a reflexão como estratégia, pode centrar-se no apoio profissional mútuo entre colegas e/ou coordenação. Pode ocorrer através da inovação curricular e/ou de cursos de formação e também por meio da investigação, quando a imagem do professor relaciona-se ao movimento de investigação-ação.

Poderíamos dizer, então, que a profissão docente requer dinamismo, um cidadão ativo e comprometido. $\mathrm{O}$ desenvolvimento desse profissional, conforme considerações anteriores, precisará ser analisado nos aspectos referentes à ação, à reflexão, à autonomia e à colaboração.

O desenvolvimento profissional do professor de matemática acontece em um contínuo movimento de dentro para fora e tende a considerar a teoria e a prática de forma interligada, não privilegiando uma em detrimento da outra (Ponte, 1998).

Dessa forma, devemos considerar os aspectos cognitivo e afetivo do professor, ao envolvê-lo em projetos, cursos, encontros. É necessário valorizar suas experiências, seus saberes que incluem crenças, concepçôes, valores e expectativas, além dos conhecimentos práticos e teóricos construídos pelo docente desde seu curso de formação inicial. Nesse sentido, Hargreaves (1998, p. 185) considera que 
(...) o desenvolvimento profissional destaca a combinação de processos formais e informais. O professor não é um objeto distante, mas torna-se o sujeito do processo de aprendizagem. É dada atenção ao conhecimento e aos aspectos cognitivos, porém, também às questōes afetivas e de relacionamento. O objetivo não é a "normalização", mas a promoção da individualidade de cada professor.

Nossa experiência, como formadora de professores que ensinam matemática e como professora, faz-nos refletir sobre as questões da complexidade educativa na qual estamos inseridos e a respeito do que seria essa individualidade nos diferentes contextos em que atuamos. Muitas vezes, desconsideramos essa problemática, ao analisarmos a atuação docente, e somos levados a reduzi-la a uma série de variáveis emergentes e à aplicação de algumas técnicas, métodos e procedimentos.

O processo de desenvolvimento profissional e de mudança dependerá principalmente do próprio professor, do quanto sua insatisfação frente a seus conhecimentos e/ou práticas de ensino atuais o inquieta e também de sua vontade e empenho em desenvolvê-los e aprimorá-los.

Embora a experiência possa ser um fator fundamental para o desenvolvimento profissional do professor, nem sempre é suficiente para responder às questôes da prática, pois a construção de soluções para muitos desses problemas requer contribuição teórica. Ao longo do exercício de sua profissão, o docente necessitará aprofundar e ampliar conhecimentos de conteúdos conceituais e didáticos, adequar-se ao movimento próprio da evolução humana, revendo o currículo que prioriza em sua ação, sua relação com os alunos e a clareza sobre o contexto no qual atua.

Em nossa sociedade atual, a instituição escolar não tem conseguido acompanhar as alterações sociais e tecnológicas ocorridas mundialmente, e cabe ao professor intervir sistematicamente na reversão dessa situação, ao promover interações sociais que gerem processos reflexivos entre os estudantes e que estes também contribuam na reestruturação dos espaços pedagógicos.

Ao pensarmos sobre a formação de um profissional que exerce seu ofício nesse contexto, precisamos refletir a respeito da aprendizagem do professor. Parece-nos importante um processo de formação profissional que se centre no contínuo hábito da reflexão, provocando o desenvolvimento profissional dos professores, que deixará de ser visto como a organização de cursos com objetivo de suprir dúvidas, dificuldades e/ou 
lacunas da formação inicial e passará a relacionar-se à criação de dispositivos e contextos que levam o docente a investir em sua carreira.

\section{Considerações finais}

Acreditamos que um dos principais impedimentos ao ensino efetivo de probabilidade e estatística na educação básica refira-se à formação dos professores que ensinam matemática nesses níveis de ensino: educação infantil, ensino fundamental e ensino médio.

Ao visualizarmos um ensino e uma aprendizagem de estocástica envolvendo a construção de modelos de fenômenos físicos, desenvolvimento e uso de estratégias de simulação e a comparação e avaliação de problemáticas diversas, precisamos considerar que essa abordagem também seja efetiva na formação dos professores. A partir dessa visão, o ensinar estatística e probabilidade torna-se sinônimo de ensinar a resolução de problemas.

Um dos aspectos importantes na formação estatística durante a educação básica refere-se à capacidade em perceber a existência da variação, à necessidade de descrever populações, a partir de coleta de dados, e à necessidade de reduzir dados primitivos, percebendo tendências e características através de sínteses e apresentação de dados. Conforme os estudantes forem progredindo em lidar com investigaçōes estatísticas, seria importante que eles entendessem a necessidade de estudar amostras, ao invés de populaçōes, e fazer inferências de amostras para populações.

É importante que os estudantes comecem a entender a natureza e os processos envolvidos em uma investigação estatística, fazendo consideraçôes que interfiram no modelo de um plano para a coleta de dados. Isso inclui reconhecer como, quando e por que ferramentas estatísticas existentes podem ser usadas para auxiliar um processo investigativo. É preciso se familiarizar com as fases específicas de um questionamento estatístico, o que inclui formular uma pergunta, planejar um estudo, coletar, organizar e analisar dados, interpretar descobertas e discutir conclusōes, implicaçôes de descobertas, assuntos para um estudo posterior.

Os estudantes precisam aprimorar as habilidades usadas no processo de investigações estatísticas: sendo capazes de organizar dados, computar índices necessários (mediana, média, intervalo de confiança), 
ou construir e representar tabelas convenientes, gráficos, plots e diagramas, feitos à mão ou com auxílio da tecnologia.

É preciso possibilitar um entendimento intuitivo e formal das principais idéias matemáticas que estão implícitas em representações estatísticas, procedimentos ou conceitos. Isso inclui entender a relação entre síntese estatística, representaçôes gráficas, e os dados primitivos nos quais eles estiverem baseados.

Ao estudar probabilidade e chance, os alunos precisam entender conceitos e palavras relacionadas à chance, incerteza e aleatoriedade, que aparecem nas nossas vidas diariamente, particularmente na mídia. Outras idéias importantes incluem a compreensão de que probabilidade é uma medida de incerteza, que modelos são úteis para simular eventos para estimar probabilidades e que, algumas vezes, as nossas intuições são incorretas e podem nos levar à conclusão errada no que se refere à probabilidade e eventos de chance.

Ao conduzir uma investigação estatística, os estudantes aprendem a interpretar resultados e a estar cientes sobre as tendências possíveis ou limitaçôes nas generalizações que podem ser obtidas dos dados. Ao conduzir este processo, os estudantes precisam aprender como interpretar resultados de uma investigação estatística e colocar questôes críticas e reflexivas sobre argumentações que se referem aos dados ou sínteses estatísticas.

Para que uma pessoa seja educada estatisticamente, ela deverá ser capaz de comunicar efetivamente as discussões sobre os resultados de investigações estatísticas, críticas estatísticas ou argumentos probabilísticos que clamam estar baseados em alguma informação. Isso envolve ser capaz de usar propriamente terminologia estatística e probabilística, viabilizando resultados de uma forma convincente, e de construir argumentos racionais baseados em informações e observaçōes (Lopes, 2004). Conforme os estudantes adquiram maior conhecimento estatístico, eles poderão também ser capazes de questionar a validade das interpretações de dados e das representações gráficas de outras pessoas, bem como as generalizações feitas com base em um único estudo ou uma pequena amostra.

A formação dos professores, atualmente, não incorpora um trabalho sistemático sobre estocástica, dificultando a possibilidade desses profissionais desenvolverem um trabalho significativo com essa temática nas salas de aula da educação básica. 
A probabilidade proporciona um modo de medir a incerteza e de mostrar aos estudantes como matematizar, como aplicar a matemática para resolver problemas reais. Para isso, recomenda-se um ensino das noçôes probabilísticas a partir de uma metodologia heurística e ativa, por meio da proposição de problemas concretos e da realização de experimentos reais ou simulados.

É importante que ensinemos aos nossos estudantes da escola básica o caráter específico da lógica probabilística, a forma de distinguir graus de incerteza e de comparar suas prediçôes e extrapolaçôes particulares como o que realmente sucede; em uma frase, que lhes ensinemos a ser donos de sua própria incerteza.

Acreditamos que o ensino e a aprendizagem que abordem o pensamento estatístico e o probabilístico, desde a educação infantil, possibilitarão a formação de um aluno com maiores possibilidades no exercício de sua cidadania, com maior poder de análise e criticidade diante de dados e índices.

A formação do educador matemático que atua ou atuará na educação básica deve prever um processo de ensino e aprendizagem de conteúdos que ocorra através da resolução de problemas, simulações e experimentos, os quais permitam ao profissional construir conhecimentos, à medida que estabelecer relaçôes com informações adquiridas e com o domínio de diferentes linguagens e formas de expressão. Consideramos que a amplitude do conceito seja mais importante que o conceito formal para o trabalho docente.

O que nos parece imprescindível é que esses profissionais tenham a possibilidade de participar de uma formação com as características defendidas por este estudo, adquirindo um conhecimento profissional que lhes dê autonomia para definir por que, quando e como se deve incluir estocástica em suas aulas.

O docente precisa apresentar pelo menos um nível de abstração superior, no que diz respeito ao conteúdo que irá trabalhar, pois somente dessa forma conseguirá estabelecer conexôes com outras áreas e/ou com o próprio conhecimento matemático e estatístico.

O conhecimento profissional didático deverá incorporar o domínio de conceitos, representaçôes, procedimentos, resolução de problemas, habilidades de exploração e investigação. Necessita que o docente tenha boa relação com a matemática, gosto e disponibilidade para se 
O ensino da estatística e da probabilidade na educação básica...

envolver em preparação das aulas, para refletir sobre os redirecionamentos no decorrer das aulas e durante momentos de formação e trabalho colaborativo.

Urge o desenvolvimento de projetos de formação inicial e contínua de professores que abordem o trabalho com a estocástica nas aulas de matemática da educação básica.

Recebido em dezembro de 2007 e aprovado em março de 2008.

\section{Nota}

1. Estocástica é o termo utilizado para tratar a probabilidade integrada à estatística.

\section{Referências}

AZCÁRATE GODED, P. El conocimiento profesional: naturaleza, fuentes, organización y desarrollo. Quadrante, Lisboa, v. 8, n. 1, p. 111-139, 1999.

BERNARDES, O. Para uma abordagem do conceito de probabilidade. Educação \& Matemática, Lisboa, n. 3, 1987.

D’AMBROSIO, U. Educação matemática: da teoria à prática. Campinas: Papirus, 1996.

D’AMBROSIO, U. Etnomatemática. 5. ed. São Paulo: Ática, 1998.

FREIRE, P. Pedagogia da autonomia: saberes necessários à prática educativa. Rio de Janeiro: Paz \& Terra, 1997.

GODINO, J.D.; BATANERO, C.; CANIIZARES, M.J. Azar y probabilidad. Madrid: Sínteses, 1987.

HARGREAVES, A. Os professores em tempos de mudanças. Alfragide: McGraw-Hill, 1998.

LOPES, C.A.E. O conhecimento profissional dos professores e suas relaçôes com estatística e probabilidade na educação infantil. 2003. Tese (Doutorado em Educação) - Faculdade de Educação, Universidade Estadual de Campinas, Campinas. 
LOPES, C.A.E. A probabilidade e a estatística no ensino fundamental: uma análise curricular. 1998. Dissertação (Mestrado em Educação) - Faculdade de Educação, Universidade Estadual de Campinas, Campinas.

LOPES, C.A.E. Literacia estatística e INAF 2002. In: FonsECA, M.C.F.R. (Org.). Letramento no Brasil: habilidades matemáticas. São Paulo: Global, 2004. p. 187-197.

MACHADO, N.J. Ensaios transversais: cidadania e educação. São Paulo: Escrituras, 1997.

MARCELO GARCÍA, C. Formação de professores: para uma mudança educativa. Lisboa: Porto, 1999.

MENDOZA, L.P.; SWIFT, J. Why teach statistics and probability: a rationale. In: Shulte, A.P.; SMART, J.R. (Ed.). Teaching statistics and probability. Reston: Yearbook National Council of Teachers of Mathematics, 1981. p. 90-100

PONTE, J.P. Da formação ao desenvolvimento profissional. In: ACTAS do PROFMAT. Lisboa: APM, 1998. p. 27-44.

POZO, J.I. (Org.). A solução de problemas: aprender a resolver, resolver para aprender. Porto Alegre: ARTMED, 1998.

SHAUGHNESSY, J.M. Research in probability and statistics: reflections and directions. In: Grouws, D.A. (Ed.). Handbook of research on mathematics teaching and learning. New York: MacMillan, 1992. p. 465-494.

SHAUGHNESSY, J.M. Research on statistics learning and reasoning. In: Lester, F. (Ed.). Second handbook of research on mathematics teaching and learning. Reston: NCTM, 2007. p. 957-1010.

SKOVSMOSE, O. Towards a philosophy of critical mathematical education. Dordrecht: Kluwer, 1994. (Mathematics education library, v. 15) 